\title{
REGIMEN HYPOTHECARIO
}

\section{CASOS DE RENUNCIA TACITA}

I. E' licito a qualquer abandonar conscientemente o seu direito, a menos que a lei expressa lh'o prohiba. Unicuique licet contemnere hac, qua pro se introducta sunt. E abandonal-o sem que ao mesmo tempo o transfira a outrem. Pelo que, entre as causas que, por vontade do titular, extinguem a hypotheca, se inclue a renuncia do credor, remissio pignoris, que aliás é um resolvente commum ao vinculo de outras obrigações. Assim, enumerando a renuncia entre os modos porque se extingue a hypotheca, não creou direito novo o decreto n. I69 A de 19 de Janeiro de 1890 , art. I I $\$ 3 .{ }^{\circ}$, reproduzido no art. $266 \$ 3 .^{\circ}$ do regulamento n. 370 de 2 de Maio seguinte: trasladou apenas disposições anteriores, quaes as da lei n. I 237 de 24 de Setembro de I 864, art. I I $\$ 3 .{ }^{\circ}$ e do decreto regulamentar n. 3453 de 26 de Abril de 1865 , art. 249 $\$ 3 .^{\circ} \mathrm{Em}$ caso analogo, o decreto n. 9549 de 23 de Janeiro de i 886 , art. i $6,33^{\circ}$, já havia recebido essa renuncia como extinctiva do penhor agricola.

2. Sómente podem ser renunciadas as hypothecas convencionaes e as judiciarias. As hypothecas legaes, ou porque falleça em umas a capacidade dos renunciantes, ou porque em outras preponderem inte- 
resses de ordem publica, não são renunciaveis. Assim, as hypothecas que garantem a bôa administração dos bens dos menores, interdictos; assim, as hypothecas constituidas em favor da mulher casada. Entretanto, em algumas legislações, se reconhece a faculdade da renuncia, mesmo tacita, nas hypothecas legaes da mulher casada: a lei franceza de I 3 de Fevereiro de 1889 , como anteriormente a de 25 de Março de 1855 , pondo fóra de seu alcance a irrevogabilidade dos pactos antenupciaes e a consideração supplementar de pertencer essa hypotheca ao dominio da ordem publica, admitte a renuncia, exercida pela mulher casada, á hypotheca que em seu favor onera os immoveis do marido, uma vez que a renuncia seja publica, authentica, expressa, ou tacita mas resultante de factos limitativamente determinados.

Entre nós não podendo os pactos antenupciaes, que determinam as hypothecas legaes, ser posteriormente alterados ou modificados; attendendo á necessidade de amparar os bens e os direitos da mulher casada: esta não póde renunciar á hypotheca legal, èm seu interesse constituida, peiorando assim, por acto voluntario, da condição que perante o marido lhe asseguram o casamento e os pactos antenupciaes. (I)

3. Para que valha na extincção da hypotheca convencional, a renuncia não está adstricta a uma fórma unica. Póde ser expressa, convencional, explicita, ou tacita, implicita, consoante á fórma que a exterioriza:-expressa, quando formaes e directos são os termos, ou signaes em que o credor a declara; tacita, si induzida de actos, factos, positivos ou negativos, que necessariamente supponham no credor a intenção de renunciar a garantia hypothecaria.

4. Ha, porém, quem conteste a extincção da hypotheca, mediante uma renuncia que, a um tempo,

(I) Lafayette Direito das Cousas, \& Igr. 
não seja expressa e especial; não comprehendendo como possa resolver direitos uma causa, que, resultante de actos, factos mais menos concludentes, se reduz muitas vezes a uma enganadora apparencia. Sem duvida, uma renuncia tacita não póde ser utilmente invocada, quando assente em actos ou factos equivocos, accommodaveis a explicações diversas, si não contrarias. Em casos duvidosos, a renuncia nunca se presume, porque nemo res suas jactare prosumitur. Mas, desse principio á absoluta proscripção da renuncia tacita em sua funcção extinctiva da hypotheca, vae immensa differença.

Rejeitar a renuncia tacita equivale a supprimir as manifestafoes indirectas da vontade em todas as relações contractuaes, eliminando o consentimento tacito;-contrariar a liberdade das convenções, por impedir que o accordo dos contrahentes produza todos os seus effeitos juridicos independentemente da fórma que o enuncie, naquelles casos em que a lei não exija um consentimento formal, expresso (A. Wable).

5. Na renuncia expressa, a vontade contractual se manifesta por signaes preorganizados, e cuja funcção natural consiste na enunciação daquella vontade. Na tacita, porém, a manifestação da vontade resulta accidentalmente dos actos que a explicam, revela-se em actos ou factos, não predestinados áquella manifestação, mas que a suppõem por isso mesmo que excluem vontade diversa, ou contraria. Porque - o facto dos contrahentes posterior ao contracto e que tem relação com o objecto principal, é a melhor explicasão da vontade que as partes tiveram no acto da celebração do mesmo contracto? E' que esse facto, positivo ou negativo, comquanto não seja por natureza disposto ás manifestações di- 
rectas da intenção dos contrahentes, comtudo a revela, e ás vezes mais inequivocamente do que as manifestações directas, interpretativas da primitiva intenção.

6. Fica reservado ao prudente arbitrio do juiz decidir si os actos ou factos, emergentes em qualquer dos casos em que se trate de renuncia tacita, são indicativos ou não da intenção contractual que se pretenda fazer prevalecer. São questões de facto, para as quaes o direito costuma proporcionar certos principios, mas principios amplos, flexiveis, que derem livre margem á apreciação prudente do magistrado, ou, como dirá Giorgi-al buon senso. Variaveis em extremo como são os actos ou factos, que accidentalmente podem enunciar a vontade contractual, quando forme, conserve ou anniquile obrigações, impossivel seria, si não perigoso, o coordenal-os, distribuil-os taxativamente.

7. Exemplificando. Costuma-se reputar tacitamente renunciada a hypotheca, em qualquer dos seguintes casos:

a) si o credor consente na venda do immovel que lhe está hypothecado;

b) si assigna conjunctamente com o devedor a escriptura de alienação do immovel, e a sua assignatura não póde ter outra explicaçăo que não a renuncia ;

c) si consente que o devedor hypotheque o immovel a outrem.

São estes os tres casos geralmente indicados em nosso direito ( $\mathrm{I}$ ).

8. No direito romano, que subsidia o nosso, o credor que prestasse consentimento á alienação da cousa hypothecada, renunciava tacitamente a hypo-

(1) Lafayette Direito das Cousas, § 276; Oliveira Machado, Man. do Off. do Reg. Ger. § 254 . 
theca: creditor qui permittit rem venire, pignus demittit (L. I 58, D., de Reg. juris). E era esse o principio constante: - si in venditione pignoris consenserit creditor, vel, ut debitor hanc rem permutet, vel donet, vel in dotem det, dicendum evit, pignus liberari: nisi salva causa pignoris sui consensit, nam solent multi salva causa pignoris sui consentire (L. $4 \$ \mathrm{I} .{ }^{0}, \mathrm{D}$., Quibus mod. hyp. solv.). Não renunciaria, pois, quem consentisse na alienação, sob reserva de subsistir o onus hypothecario na cousa alienada.

Ainda mais.

Caso não se effectuasse a venda consentida pelo credor, se reputava insistente o onus da hypotheca. O devedor não se podia valer do consentimento prestado: nam sicut debitori, ita et crentitori pristinum jus restituitur (Leis I $0,8 \$ 6, D$. cit.).

Não assim, quando o devedor viesse a readquirir a cousa, que houvera sido alienada com o consentimento do credor. Duas opiniões disputaram a solução do caso. Uma - doutrinava que o onus hypothecario revivia desde o momento em que a cousa alienada reentrasse no patrimonio do primitivo devedor, propter verbum futurarum rerum, quod in generalibus hypothecis poni solitum est.

Outra, ao contrario dava por extinctos os direitos do credor hypothecario, sem admittir a possibilidade de sua renovação. Foi essa a solução que prevaleceu (I) na legislação de Justiniano, por parecerindignum esse eandem, utpote ab initio et suppositam vindicare, vel tenentem inquietare (Cod. de Remiss. pign., const. ultima).

9. Requer-se, porém, que os actos do consentimento sejam univocos, incondicionaes, nisi salva

(I) Mackeldey procura sustentar o contrario, e cita a const. i. a do Cod. de remiss. pign., que não vem ao caso. Man. de Droit Romain, $\S 362$ not. 12. 
causa pignoris, porquanto muitos costumam salva causa pignoris consentire. Por isso é que -- ao credor ficava sempre salvo o direito de provar que os actos arguidos não eram indicativos da renuncia ; replicabitur de dolo et fraude, como no caso da lei $3 .^{\mathrm{a}}$, D., de Pignorat action.

A presumpção é uma relação moraimente certa e logicamente uniroca do facto conhecido para o facto a conhecer; e essa relação seria equivoca, se os mesmos factos fossem susceptiveis de mais de uma explicação.

Mas qual o fundamento dessa presumpção na renuncia tacita?

Presume-se que o credor, consentindo na venda da cousa hypothecada, renunciou tacitamente á hypotheca, porque o consentimento, não sendo indispensavel para a validade da alienação, deve ter uma explicação unica, a de renunciar o direito. Ao contrario, o consentimento do credor se reputaria um acto inutil, uma formalidade ociosa, o que a lei nunca presume (I).

Io. Si esse é o fundamento em que assenta a renuncia presumida, não parece que, em direito patrio, resigne a garantia hypothecaria o credor que, pura e simplesmente:

a) consente na venda do immovel hypothecado; ou que

b) assigna conjunctamente com o devedor a escriptura de alienação do mesmo immovel.

(I) Baudry - Lacantinerie : - « Un creancier hypothécaire concourt á la vente de l'immeuble hypothéqué, consentie par le débiteur, et signe l'acte qui en est dressé; renonce-t-il ainsi tacitement á son hypothéque? L'affirmative devra être admise le plus souvent, parce qu'il será impossible de donner une auire explication de la conduite du créancier. Son consentement n'était pas nécessaire apparemment pour la validité de la vente; alors qu'est-il venu faire, sinon rassurer l'acquereur en renongant au profil de celui-ci á son hypotheque? Préc. de Droit civil, n. I499. 
E a presumpção desapparece, porque desapparece o seu fundamento. Com effeito, si a intervenção do consentimento do credor na alienação do immovel hypothecado não accrescenta uma só linha á validade do acto, não é menos certo, que para outros effeitos juridicos essa intervenção é solicitada. E assim, o consentimento do credor, não se reduzindo a um acto inutil, a uma formalidade van, deve ter outra explicação que não a renuncia tacita de direitos.

Ora, torna-se indispensavel a outorga do credor nas alienações dos immoveis gravados por hypotheca; o consentimento tem uma explicafão legal, que, por isso mesmo, exclúe a da renuncia tacita.

a) No dominio do Codigo Criminal, vigente ao tempo da Lei n. 1237 de 24 de Setembro de I 864 , e á epoca em que foram promulgados os decretos ns. 169 A de 19 de Janeiro de 1890 e 370 de 2 de Maio seguinte, configurava-se um crime publico a alheafão da cousa propria especialmente hypothecada a terceiro (art. $264 \mathbb{S} 3 .^{\circ}$ ). Assim explicava-se o consentimento do credor hypothecario, - esse terceiro, cujos interesses a lei salvaguardava tornando delictuosa a alheação: a outorga vinha isentar da responsabilidade criminal o vendedor da cousa propria especialmente hypothecada. Essa significação, e não outra - a de renuncia, tinha o consentimento do credor.

E' certo que esse motivo ou essa explicação não mais prepondera, depois da substituição do velho codigo; mas demonstra que o legislador de 1890 , como o de $\mathrm{I} 864$, não podia reputar como renuncia tacita a simples outorga do credor na escriptura de alienação do immovel hypothecado.

Occorre mais.

b) Do estudo comparativo das disposições contidas nos arts. 2 I $7 \$ 33^{\circ}, 257$, e 27 I do decreto citado 
n. 370 de 2 de Maio de 1890 , resulta que o consentimento do credor é solicitado na alheação do immovel hypothecado. "Aquelle que adquirir o immovel hypothecado e nos trinta dias depois da transmissão não tratar da remissão da hypotheca, fica sujeito á excussão do immovel. " Disposição do art. $217 \$ 3 \cdot{ }^{\circ}$, copiada do art. $240 \$ 3 \cdot{ }^{\circ}$ do regulamento de 1865 . E por essa falta de remissão, o adquirente fica sujeito : ao sequestro e á execução da acção; ás custas e despezas judiciaes de desapropriação; á differença do preço da avaliação e alienação; á acção de perdas e damnos pela deterioração do immovel (art. 27I).

A hypotheca produz um direito real contra terceiros que venham a adquirir o immovel, por titulo posterior á instituição do onus; e o terceiro que, adquirindo o immovel assim gravado, não tratar de remil-o dentro dos trinta dias que se seguirem á transmissão, fica sujeito á excussão do immovel, caso o preço da alienação não baste para o pagamento da divida hypothecaria.

A lei previne dous casos:

Ou o preço da alienação do immovel onerado é insufficiente para a solução integral do debito;

Ou tal preço basta para o mesmo pagamento.

Na primeira hypothese é indispensavel a remissão do immovel, a menos que o adquirente queira supportar a expropriação judicial. A remissão não é tão sómente adaptada e applicavel ao caso, mas ainda - necessaria (art. 269). Na segunda hypothese, embora não seja applicavel e necessaria a remissão do immovel, a lei formalmente exige que o credor outorgue e assigne, com o adquirente, a escriptura de venda do mesmo immove! (art 269). De modo que, para evitar a excussão, o adquirente deve remir o immovel, si o preço da alienação fôr inferior á 


\section{$-53-$}

divida ; não é, porém, necessaria a remissão, no caso de ser o préço sufficiente para o pagamento, mas ainda ahi - é indispensavel que o credor outorgue e assigne a escriptura.

Conseguintemente, a intervenção do credor corresponde a uma exigencia da lei; - é necessaria para que o adquirente evite a excussão, mesmo que o preço da alienação baste para a solução dos encargos hypothecarios. Assim sendo, o consentimento do credor, prestado pura e simplesmente, não se póde interpretar como renuncia tacita á hypotheca; deixa de ser um acto ocioso.

I I. As mesmas soluções se applicam ao caso em que o credor assigna conjunctamente com o devedor a escriptura de alienação do immovel. (I).

I2. Por ultimo. Considera-se tacitamente renunciada a hypotheca, si o credor consente que o devedor hypotheque o immovel a outrem, e o faz sem reservas. Mas semelhante consentimento póde não implicar renuncia total. Ao credor assiste o direito de, em beneficio de outro, desistir da prelação em que ficou constituido, sem que de tal se infira renuncia á garantia. A prelação é uma qualidade extrinseca da hypotheca; desapparece, por vontade do credor, mas não prejudica á essencia daquella obrigação. Quando, porém, o credor abdica o direito de sequela, por isso mesmo se extingue e se anniquila a hypotheca, porque desapparece a essencia, a substancia dessa relaçăo juridica. Em ambos os casos, a difficuldade está por inteiro no apurar a qual das duas intenções, ou si a todas obedeceu o credor prestando o seu consentimento.

(1)..... il faut que ce consentiment soit formel; et ne suffirait pas qu'i ềt signé l'acte: la simple signature pourrait être regardéc comme une surprise qui n'aurait pas d'effet (Merlin, Repert., Hypothéques, sect. I, § XIII). 
$\mathrm{Na}$ duvida, deve-se presumir que o credor apenas desistiu da prelação. Lorsque le premier créancier a consenti que le debiteur obligeât la chose dejà hypothéquée à un second, on ne présume pas en ce cas qu'il ait voulu remettre absolument son droit, mais seulement céder l'avantage de la priorité au nouveau créancier (Merlin, Repert., Hipothéques, sect. I, § XIII). (I).

O direito romano figurava uma hypothese caracteristica :- Si o devedor, depois de ter hypothecado uma cousa a um credor, mediante o consentimento deste dá posteriormente a mesma garantia a outro credor, o segundo credor tem prelação sobre o prineiro, secundus potior erit. Mas, dado o caso de ter sido pago o segundo credor, permanece a primeira hypotheca? 'E' uma questão de facto, responde Marciano, que depende da intenção dos contrahentes: - ou o primeiro credor, consentindo na hypotheca a outrem, renunciou á sua garantia in totum, ou renunciou apenas á preferencia, ut ordo servetur (L. I 2 \&, D., Qui pot. in pign.).

"Si o credor assignasse a escriptura de hypotheca do immovel a outrem, como notario ou como testemunha, não se poderia presumir a renuncia, (2). Não assim, quando a escriptura declarasse o immovel livre e desembargado, fundum nulli alii esse obligatum, solução tambem prevista no direito romano (L. 9 I. ${ }^{\circ}$, D., Quibus mod. pign. solv.).

(I) Laurent, Cours elément. de Dr. Civil, 4574.

(2) Lafayette, cit., \& 276 , not. I 3 .

São Paulo, Agosto de 1893. 